\title{
Presentation of the Diverticulum of the Caecum, Cause of the Acute Abdomen
}

\author{
Afrim Avdaj ${ }^{*}$, Nexhmi Hyseni2 ${ }^{*}$, Curr Gjocaj ${ }^{3}$, Agron Bytyqi ${ }^{4}$, Artur Avdaj $^{5}$, \\ Hatim Baxhaku1 \\ ${ }^{1}$ Division of Surgery, Regional Hospital “Primarius Daut Mustafa”, Prizren, Kosova \\ ${ }^{2}$ Surgical Pediatric Clinic, Department of Pediatric Surgery, University Clinic Centre of Pristina, Prishtina, Kosovo \\ ${ }^{3}$ Hospital and University Clinical Service of Kosovo, Prishtina, Kosovo \\ "Division of Education, Regional Hospital "Primarius Daut Mustafa", Prizren, Kosova \\ ${ }^{5}$ Medical Faculty in Pristina, Pristina, Kosovo \\ Email: *nexhmi_h@yahoo.com
}

Received 17 December 2015; accepted 11 February 2016; published 14 February 2016

Copyright (C) 2016 by authors and Scientific Research Publishing Inc.

This work is licensed under the Creative Commons Attribution International License (CC BY).

http://creativecommons.org/licenses/by/4.0/

(c) (i) Open Access

\begin{abstract}
Solitary caecal diverticulum is an uncommon entity and therefore it is difficult to diagnose except during surgery exploration. It is extremely difficult to differentiate it preoperatively from acute appendicitis. We report a case of an enlarged colon segment, presenting macroscopically as tumor diverticulum in a 27-year-old female patient, presenting with a 2 day history of a severe abdominal right lower quadrant pain with accompanying anorexia, nausea, vomiting and high body temperature. After clinical assessment, laboratory examination, X-ray, and CT are performed, the indication for surgical treatment is set.
\end{abstract}

\section{Keywords}

\section{Caecum Diverticulum, Acute Abdomen, Abdominal Pain}

\section{Introduction}

Caecal diverticulum is an abnormal sac or pouch protruding from the wall of a hollow organ such as colon, a condition that is rare and becomes more common with increasing age. Often the diagnosis of caecal diverticulitis cab can be assured based on the history and physical examination is extremely difficult to differentiate it preoperatively from acute appendicitis. If the infection originates from the caecal divetrticulum, the entire peritoneal cavity can be contamined. This complication is rare, but immediate surgical intervention is needed.

"Corresponding author.

How to cite this paper: Avdaj, A., Hyseni, N., Gjocaj, C., Bytyqi, A., Avdaj, A. and Baxhaku, H. (2016) Presentation of the Diverticulum of the Caecum, Cause of the Acute Abdomen. Surgical Science, 7, 54-57. 


\section{Case Report}

A 27-year-old patient presented at the hospital's Emergency Department with a 2 day history of a severe abdominal right lower quadrant pain with accompanying anorexia, nausea, vomiting and high temperature. Physical examination revealed clinical signs of acute abdomen with local rebound tenderness. The vital signs were as follows: temperature $38.7^{\circ} \mathrm{C}$, pulse rate 100 beats/min, blood pressure $125 / 75 \mathrm{mmHg}$, and respiratory rate 25/min. The laboratory test results on admission were within the normal limits except the elevated white blood cell (WBC) count of $16,200 / \mu \mathrm{L}$. During family history, the patient denied associated diseases and sensitivity to drugs. After clinical assessment and laboratory, abdominal X-ray showed a distended bowel with air-fluid levels, abdominal ultrasound and CT showed free liquid on peritoneal space.

Indication for surgical exploration was set and it was performed under general anesthesia. Operative course: with lower and partially upper medial laparotomy of the abdomen was opened, serous-fibrinous liquid was aspirated, during exploration of the abdomen of an enlarged tumor was found at the level of cecum, macroscopically looking like diverticulum, with red walls and gangrenous change (Figure 1). The appendix was found to be normal.

Diverticulectomy was performed and caecum was closed with two layers, an appendectomy was also performed. After a good washout, abdominal drainage of Douglas cavity was done.

Histopathological examination described an appendix $11 \mathrm{~cm}$ length, with mucosal infiltrate. Second histological part had fragments of caecal diverticulum (Figure 2).

Postoperative course was uneventful; the patient was initially followed in Intensive Care Unit. The patient recovered in the surgical ward for two last days, biochemical laboratory tests were in reference value. Abdominal drain was removed on the 5th post-operative day while epi-fascial Redon drain was removed in the 7th post-operative day. The patient was discharged on the 7th postoperative day, in good condition.

\section{Discussion}

Right-sided colonic diverticulitis was first described in 1912 by Potier [1]. Caecal diverticulitis is a relatively uncommon condition, but presents an important differential diagnosis of right iliac fossa pain. The condition has a higher prevalence in Far East Asian populations [2] and is more common in men [3]. The age of patients in published case reports ranges from 20 to 51 years, but the average age of presentation appears to be early to mid-40s [4], while our case is a female patient aged 27 years old. Although the etiology of caecal diverticula is
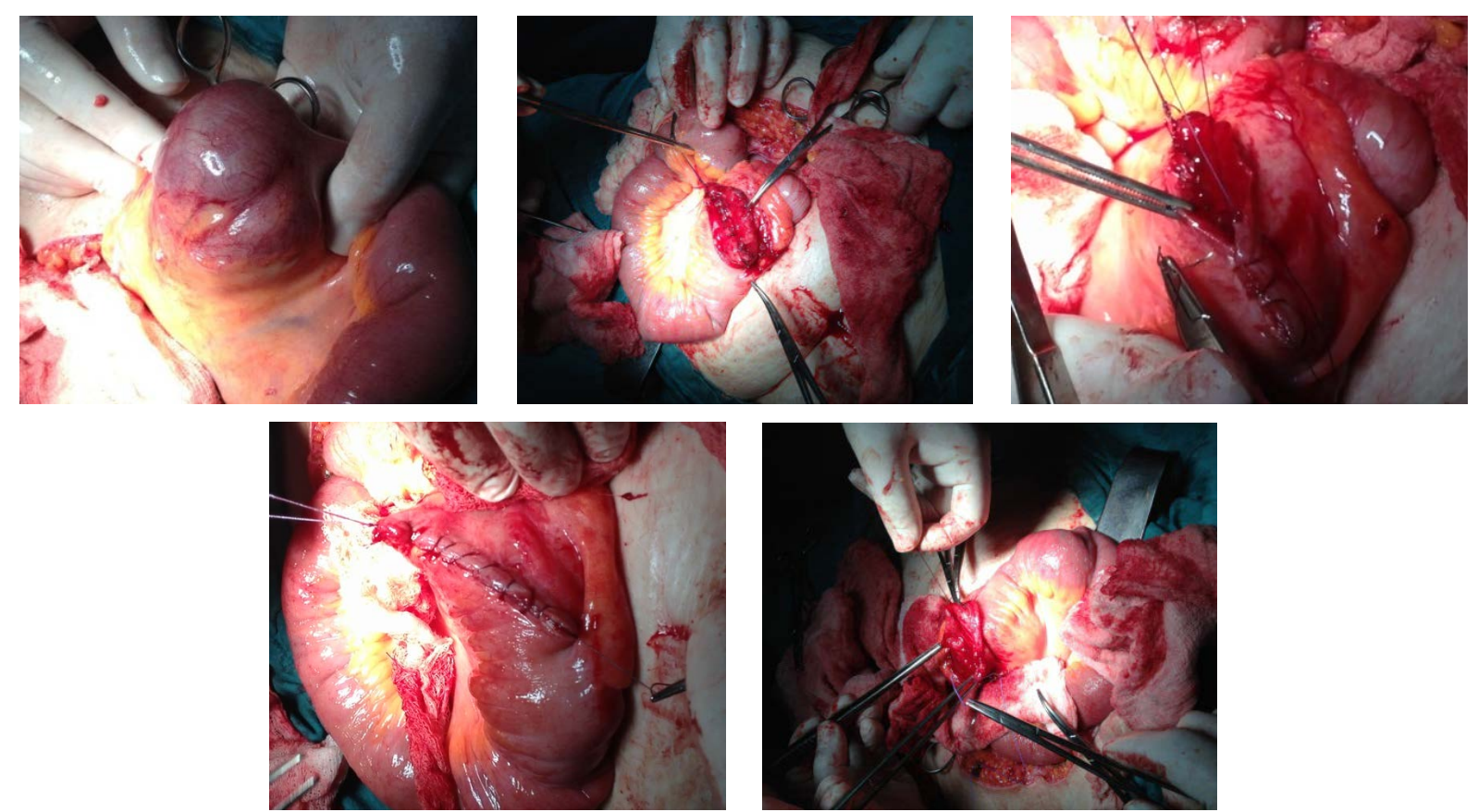

Figure 1. Intraoperative images of caecal diverticulitis and diverticulectomy. 

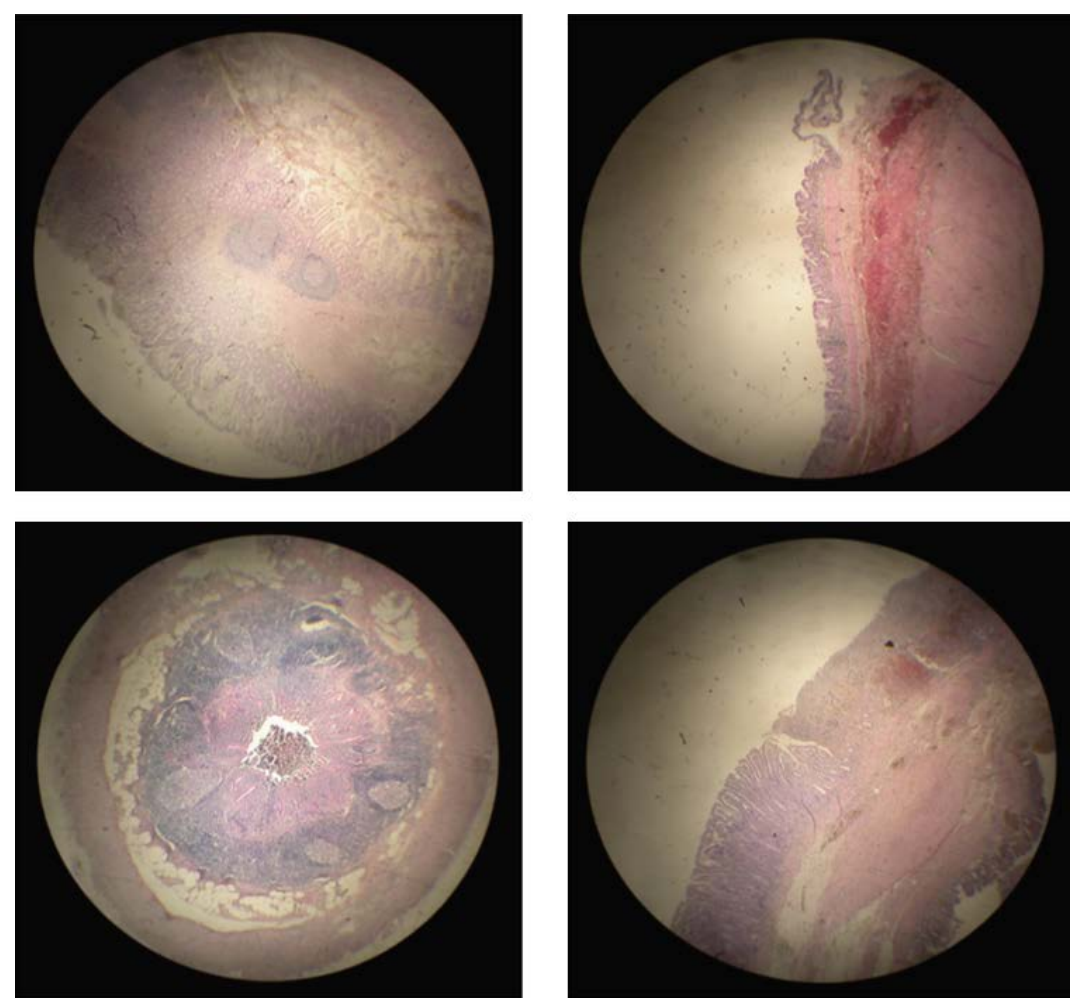

Figure 2. Histological sections showing caecal diverticulum-images using increasing microscope resolution settings.

still indefinite, they are thought to be linked to a congenital defect, whereby the vestigial caecal out pouching can be considered a "duplication" of the appendix [5]. Clinically, caecal diverticulitis usually presents with right iliac fossa pain, often associated with fever, nausea/vomiting, which is why it is so easily mistaken for acute appendicitis [6]. The majorities of cecum diverticulitis are developed in the frontal surface of the colon and are usually asymptomatic. In case of inflammation or perforation, the clinical symptoms and signs of the disease mimic acute appendicitis. Even during the operation sometimes the caecal diverticulitis is indistinguishable from acute appendicitis and carcinoma of the cecum [7]-[11]. Indeed, it is almost always diagnosed during surgical intervention rather than preoperatively. The main complications to which the condition may lead include perforation, abscess formation, hemorrhage and torsion [4] [12]-[14]. In the past, conservative management (antibiotics alone) has been recommended. However, most modern case reports describe surgical treatment options ranging from localized excision to radical resection [15] [16]. This case once again illustrates the clinical significance of caecal diverticulitis as an important differential entity to be considered in patients presenting with signs and symptoms of acute appendicitis; it also demonstrates that the condition may be more common in Caucasian patients than previously reported. With preoperative diagnosis continuing to pose a dilemma, the role of ultrasound and CT certainly requires further consideration [3] [9] [16]. With increased awareness, training and experience, it should be possible to manage most cases of caecal diverticulitis using laparoscopic technique for both diagnosis and definitive treatment.

In our case laparotomy at the emergency was conducted compared with literature data there is a possibility of laparoscopy treatment of this pathology with the possibility of conversion into open treatment.

Although, in this particular case, the decision was made to convert to open procedure, there is clearly scope for raising awareness of the condition, particularly among surgical trainees, and advocating the use of laparoscopic techniques under such circumstances; this would lead to increased experience and confidence in laparoscopy for diagnosis and management of caecal diverticulitis and, based on the less invasive nature, this would also be beneficial to the patient.

There is no standard surgical procedure for the treatment of an acute, inflamed solitary caecal diverticulum, since the surgical approaches are not evidence-based. The choice of the surgical approach should be tailored to 
the operative findings and depends on the experience of the surgeon.

\section{Conclusion}

Diverticulitis of the cecum is a rare entity. It may be difficult to make a differential diagnosis of cecal diverticulitis from acute appendicitis or of patients complaining of right iliac fossa pain. However, the surgeon should be taken into consideration during the differential diagnosis as one of possible causes of acute abdomen.

\section{Financial or Other Competing Interests}

None.

\section{References}

[1] Potier, F. (1912) Diverticulite et appendicite. Bulletins et Memoires de la Societe Anatomique de Paris, 71, $29-31$.

[2] Kurer, M.A. (2007) Solitary Caecal Diverticulitis as an Unusual Cause of Right Iliac Fossa Mass: A Case Report. Journal of Medical Case Reports, 1, 132. http://dx.doi.org/10.1186/1752-1947-1-132

[3] Malek, L., Sultan, A., Abbas, M., et al. (2009) Perforated Caecal Diverticulitis Mimicking an Acute Appendicitis: A Case Report. Cases Journal, 2, 7901. http://dx.doi.org/10.4076/1757-1626-2-7901

[4] Abogunrin, F.A., Arya, N., Somerville, J.E., et al. (2005) Solitary caecal Diverticulitis-A Rare Cause of Right Iliac Fossa Pain. The Ulster Medical Journal, 74, 132-133.

[5] Waugh, T.R. (1941) Appendix Vermiformis Duplex. Archives of Surgery, 42, 311-320. http://dx.doi.org/10.1001/archsurg.1941.01210080111006

[6] Shyung, L.-R., Lin, S.-C., Shih, S.-C., Kao, C.-R. and Chou, S.-Y. (2003) Decision Making in Right-Sided Diverticulitis. World Journal of Gastroenterology, 9, 606-608.

[7] Papapolychroniadis, C., Kaimakis, D., Fotiadis, P., et al. (2004) Perforated Diverticulum of the Caecum. A Difficult Preoperative Diagnosis. Report of 2 Cases and Review of the Literature. Techniques in Coloproctology, 8, S116-S118. http://dx.doi.org/10.1007/s10151-004-0129-6

[8] Mudatsakis, N., Nikolaou, M., Krithinakis, K., Matalliotakis, M., Politis, N. and Andreadakis, E. (2014) Solitary Cecal Diverticulitis: An Unusual Cause of Acute Right Iliac Fossa Pain-A Case Report and Review of the Literature. Case Reports in Surgery, 2014, Article ID: 131452. http://dx.doi.org/10.1155/2014/131452

[9] Griffiths, E.A. and Date, R.S. (2007) Acute Presentation of a Solitary Caecal Diverticulum: A Case Report. Journal of Medical Case Reports, 1, 129. http://dx.doi.org/10.1186/1752-1947-1-129

[10] Kroening, H.L. and Rai, S. (2013) Caecal Diverticulitis, an Uncommon Mimic of Appendicitis. BMJ Case Reports, 2013. http://dx.doi.org/10.1136/bcr-2012-007820

[11] Uwechue, R., Richards, E. andrer, M. (2012) Stapled Diverticulectomy for Solitary Caecal Diverticulitis. Annals of the Royal College of Surgeons of England, 94, e235-e236. http://dx.doi.org/10.1308/003588412X13373405387131

[12] Paramythiotis, D., Papadopoulos, V.N., Michalopoulos, A., Panagiotou, D., Panidis, S., Digkas, E., Papaefthymiou, L. and Basdanis, G. (2011) Inflammation of Solitary Caecal Diverticula: A Rare Aetiology of Acute Abdominal Pain [Corrected]. Techniques in Coloproctology, 15, S127. http://dx.doi.org/10.1007/s10151-011-0765-6

[13] Malek, L., Sultan, A., Abbas, M. and Al-Awadhi, N. (2009) Perforated Caecal Diverticulitis Mimicking an Acute Appendicitis: A Case Report. Cases Journal, 2, 7901. http://dx.doi.org/10.4076/1757-1626-2-7901

[14] Cole, M., Ayantunde, A.A. and Payne, J. (2009) Caecal Diverticulitis Presenting as Acute Appendicitis: A Case Report. World Journal of Emergency Surgery: WJES, 4, 29. http://dx.doi.org/10.1186/1749-7922-4-29

[15] Kachroo, N., Sivakumar, R., Hakim, A., Semeraro, D. and Speake, W. (2009) An Unusual Presentation of Caecal Diverticulitis. BMJ Case Reports, 2009. http://dx.doi.org/10.1136/bcr.03.2009.1702

[16] Lim, K.G. (1999) Caecal Diverticulitis-A Review of Eight Cases in Taiping, Malaysia. Medical Journal of Malaysia, 54, 230-234. 